\title{
A Conceptual View of the Ocean Atmosphere Climate System: Armchair Oceanography and Global Historic Fish Catch
}

\author{
Brenda J. Topliss \\ Bedford Institute of Oceanography. Dartmouth, Nova Scotia Canada
}

Does the atmosphere drive the oceans or do the oceans drive the atmosphere? That was one of the questions asked at the 2000 Chapman conference (American Geophysical Union) on the North Atlantic Oscillation. At such a meeting this question could appear to be targeted to the theoretical or numerical modelling community. As an oceans community we often see potential evidence for the longer-term influence of the oceans on the global climate system. Our understanding of ocean thermohaline circulation, with its sinks and sources, is linked to the concepts of oceanatmosphere interactions and feedback systems. But what does the presence of feedback in a physical system really imply? A linear system does not have feedback. So a system must be non-linear to be able to produce, or receive, a feedback signal. Quantifying natural systems involves considering both inherent and measurement noise. So now a discussion of non-linear physical systems, with noise, sounds as though we should be passing our question back to the engineering world of signal processing. Or does it?

\section{A "Gedanken" Experiment}

How are ocean-atmosphere communications conducted? In climate studies we consider the atmosphere to have no short-term memory. Without a memory the land-atmosphere system this year has no way to remember or repeat what happened last year. All is noise. Alternatively the ocean is considered to act as the memory for the land/atmosphere system since the oceans store and release heat over a number of years. Hence we could regard any "memory" in land signals to be a "reminder or feedback" via the oceans. Viewed another way, the question becomes 'can we associate ocean feedback with repeated or persistent signals in seasonal air temperatures?

But the oceans are not simply passive messengers. The oceans generate their own responses to atmospheric signals, for example upwelling, circulation and frontal processes. So now imagine the climate system as a global company, consider two of its executives, Mother Nature and Venus. Mother Nature is the chief executive officer (CEO) who, like the atmosphere, encompasses the land, ocean and ice surfaces. Consider Venus as a vice-president (VP) responsible for the Aquatic environment. Imagine also the workers in various regional, marine subsidiaries.

Both executives have their own agendas (signals) but the two do communicate with each other implying the existence of a non-linear "management" system. We might gain useful "investment" information on this company if we knew the orders issued by the CEO. But where the VP also has a voice (implicit in a non-linear system) such information might show a weak or variable relationship to company profits. Instead of searching for who is giving what orders, suppose we could simply access the company minutes, gain insider-information, "listen" to internal communications? For executive meetings on Aquatic issues those minutes would include details of what had been achieved via both prior routine and crisis management decisions. A busy CEO can't be expected to remember every detail, until it is brought up, effectively as a reminder from the VP, at these meetings. Hence company minutes also serve as the CEO's memory of prior activities.

When both the CEO and the VP are in complete unison, company directives are strong. This may be a period when it is easy to relate the worker's output to the CEO's orders-a near linear system. But what has been happening when the minutes indicate an apparently random relationship between the instructions of the last meeting and the actions reported in the current meeting? With such a lack of communications how would the workers' productivity be affected? With a powerful, global company what would constitute "noise", less than 100\% effective communication between groups, less than $100 \%$ response by any group of workers? Another element of noise could be its short-term and/or external nature, a take-over bid, a foreign-political crisis or unpredictable weather-related 
factors. What results when such external events happen at a time when the CEO and VP are not working well together? Would those internal company minutes reveal discussions on decreased profits, cutbacks and redundancies?

\section{The Mathematical Experiment}

Anthropomorphized analogies help in the initial exploration and communication of a topic; further exploration can be achieved by mathematics. In a mathematical simulation the two executives are replaced by two simple sine waves, A and B, each of equal magnitude but different periods (agendas). The non-linearity is expressed by a product term, $\mathrm{pAB}$, where $p$ represents the level of interaction. A random noise signal is added with amplitude $\mathrm{q}$.

$$
\mathrm{A}+\mathrm{B}+\mathrm{pAB}+\mathrm{q}^{*} \text { Noise }
$$

This expression represents the components of the system but it does not easily demonstrate the feedback signal. Whether in the "Gedanken" or the climate system, feedback is represented by the repetition of information (this year versus last year). The correlation of a data series with itself, that is autocorrelation, is one of the simplest ways to relate a system to itself. Using the above simple expression we can run simulations to explore the concept that, in the statistical domain, the autocorrelation is the internal communication within a non-linear system, it is those "company minutes".

Most statistical analysis and testing techniques rely on the underlying mechanism being "stationary". A hypothetical stationary, but non-linear system, would have a constant level of feedback. Traditionally the existence of autocorrelation in a data series is either a problem to be removed by transformation or it is used to infer a weaker relationship than implied by any correlation relationship. In the latter case the level of autocorrelation is used to downgrade either a correlation coefficient or its significance level. (These comments exclude auto-regressive techniques such as ARIMA.)

If a system is non-stationary then the level of feedback continually changes and could even exhibit patterns or cycles. The simulation experiment is to calculate a one-year lag, moving autocorrelation over a small number of years. For example take a 1000-year time series and lag it one year to create a second time series. Then perform a cross-correlation over 11 years, advance one year in both series and repeat the process for another 11 years and so on. This analysis generates a new time series. A strongly linear system put through this filtering process would produce an output with a nearly constant level of moving autocorrelation (Figure 1a). However, if the output changes over the full range of the correlation scale $( \pm 1)$ we have a non-stationary system (Figure 1c) and there are few statistical theories and hence "rules and tests" for such systems.

The sine-wave simulations (Figures $1 \mathrm{~b}$ and 1c) demonstrate long-term variations in feedback for a non-linear system. The addition of random noise can cause abrupt transitions to decade-long negative feedback states (Figure 1c). The high frequency random noise adds data points both in and out of phase with the one-year time lag of the autocorrelation technique. When there is little "direction" from the dominant signals this out of phase information can produce a negative relationship.

For a given set of sine waves and correlation window ( 9 and 11 years in the above example), the greater the level of non-linearity, p, the smaller the level of noise, $q$, required to produce negative feedback (and vice-versa). So this type of filter can emphasize weak linearity in a complex system. The correlation window is effectively a third cycle in the simulation and could be viewed as a bio-environment response term. By analogy a workers' employment term needs to be long enough to experience changes in management schemes.

\section{The Atmosphere}

For the natural system we cannot get at the isolated components, we cannot meet with Mother Nature, the CEO or Venus, the VP. All our information is already non-linear and the result of long established communications practises. How do we access the company minutes? Going back to the ideas of memory in the land-ocean system, we need to look for repetition in the atmospheric system. We need to calculate the varying level of repetition in air temperatures on the assumption that this is the ocean feedback. To do this a new filter called MONACLE* has been developed that provides a simple means of exploring non-stationary systems via moving serial autocorrelation analysis. That is, take an air temperature time series and lag it one year to create a second time series. Then perform a cross-correlation over an odd-number of years, say 9 $(2 n+1)$ years, advance one year in both series and repeat the process for another nine years and so on. This generates a new time series centred to year $5(n+1)$. So MONACLE is just a first step (lag) serial autocorrelation applied to seasonal air temperature data but via a three-component filter of season start-month, season length and environment response time (e.g. 9 years).

So the next question is where and when can we find the relevant oceanic feedback. For ocean feedback the "where" are coastal regions, but "when" will the communications between the two systems be at their strongest? Perhaps "internal" communications go on all year round but are masked by other seasonal signals or perhaps they are a seasonal event. This study has not yet fully answered these questions.

All preliminary analyses indicate that MONACLE filtered air-temperatures are consistently easier to interpret for autumn. What could be special about autumn? In autumn the oceans retain heat longer than the land/atmosphere system so conceptually the oceans are in a "position to provide feedback". The start and 
(a)

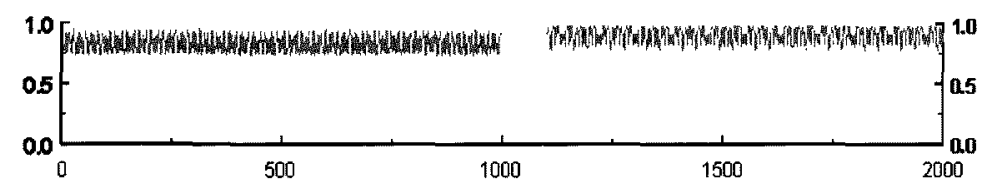

(b)

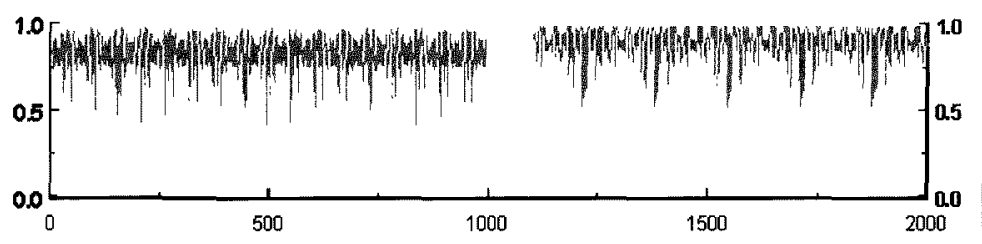

(c)

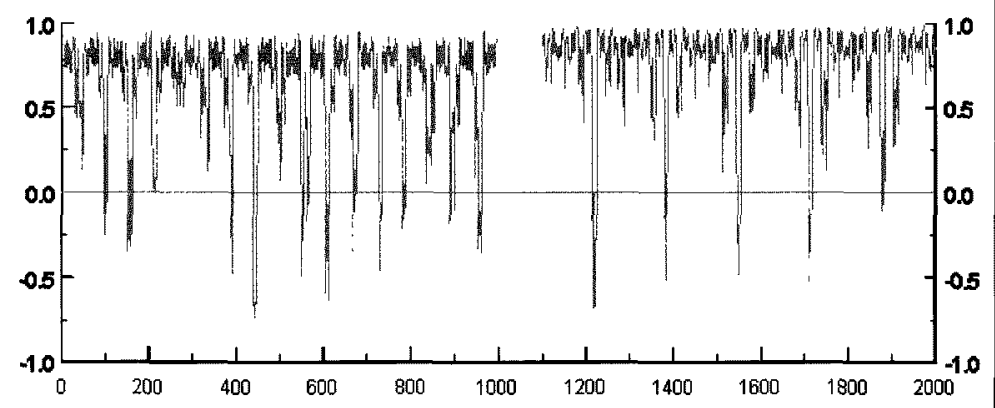

Figure 1. Thousand-year time series of (left) 9-year moving-window autocorrelation series for sine waves $A$ and $B$ of 11 and 57 years, $p=0.9$ and $q=0.7$ and (right) an 11-year moving window with sine waves of 15 and 33 years, $p=0.75$ and $q=0.2$, for (a) linear $A+B(b)$ non-linear $A+B+p A B(c)$ non-linear plus noise [note vertical scale change].
Ottestad (1969) gave an early demonstration of the link between climate and the 90-year catch of Norwegian Cod in the fjord at Bodo. Climate is considered as an important, contributing factor to the decline of northern cod off eastern Canada (Drinkwater, 2000). Dickson and Brander (1993) related a change in the West Greenland cod fisheries to warm water and large scale climate conditions corresponding to the occurrence of the Russell cycle (Russell et al., 1971) in the English Channel. Kondo (1988), Kawasaki (1992) and others have noted the regime shift between anchovies and sardines off Japan. Both the Peruvian and U.S. West Coast sardine and anchovy populations have undergone periodic changes. The larger-scale variations in the sardine catch off Portugal have been related to coastal upwelling (Dickson et al., 1988). The $18^{\text {th }}$ and $19^{\text {th }}$ century herring catch alternated between the Swedish Bohuslan and Norwegian spring herring fisheries (Devold, 1963), whereas little has been determined for the $19^{\text {th }}$ century variations in mackerel off the U.S. East Coast. Changes in the Alaskan salmon catch have been discussed in terms of largescale ocean processes and atmospheric influences (Hare and Francis, 1995). In the length of this optimum season may vary with geography; autumn in the U.K. or Canada may not occur at the same time as fall in the U.S., nor in Portugal nor in Norway. Limited data for the Southern Hemisphere confirm the "optimum-communication" season occurs in the austral autumn.

\section{The Marine Workers}

The MONACLE analysis produces a time series of potential feedback. How do we know this is information (the Company minutes) rather than noise or alternatively the minutes of another subsidiaries (e.g. the Hydrology or the Ice-Cap subsidiary)? To confirm this we need to match these new time series to the activities of different groups of marine or aquatic workers. But it is important to note that we are not seeking a cause and effect relationship. A feedback time series (or company minutes) does not force, direct or cause variations in marine activities, rather it can be regarded as a passive index or a "recording" of information back to the CEO, who in due course, may utilize such feedback in further actions.

Marine fisheries studies have a long history of debate on the relative importance of climate and population dynamics. Scores of studies have noted apparent climatic and even cyclic behavior of some fish populations (covered in books, special issues and reports such as Cushing, 1982; Beamish, 1995; Bakun, 1996; FAO, 1997).
Southern Hemisphere catch data are of shorter duration and limited to the second half of the $20^{\text {th }}$ century. South African pilchards, hake, Antarctic krill and seal populations have all been under debate for climatic influences. The tropics have always had a paucity of catch data; the time series are shorter, species live shorter lives and tend to exhibit more rapid, inter-annual variations in catch or populations. (By analogy, are they the casual/temporary workers in the company?)

Similarly there are numerous studies where although climatic or environmental influences have been hypothesised, supporting evidence has been either lacking or ambiguous. The Dungeness crab catch data, for the three west coast states of the U.S., is a classic example of the latter (McConnaughey and Armstrong, 1995). Another has been the search for climatic influences on long-term lobster catches along the Canadian and U.S. Atlantic coast (Drinkwater et al., 1991; 1996).

Historically fish catch data have been recorded because of their commercial value to humankind. This study is not about predicting fish catch data. Rather catch data are often the only source of long marine time series, having a longer history than even marine biology studies. One drawback is that these historic catch data are in a variety of units (barrels, imperial, and metric) and rarely come with unit effort data. In this text all 
(a)

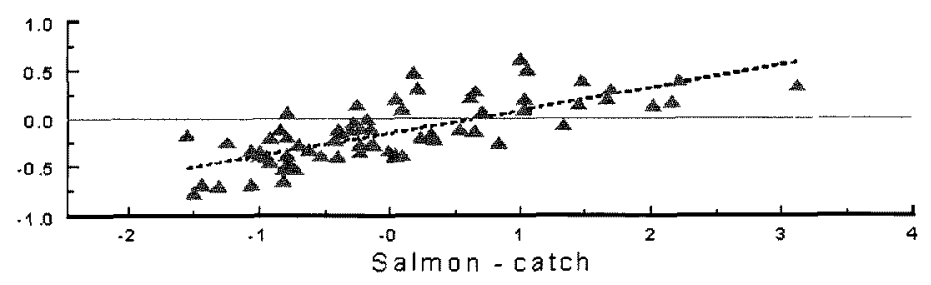

(b)

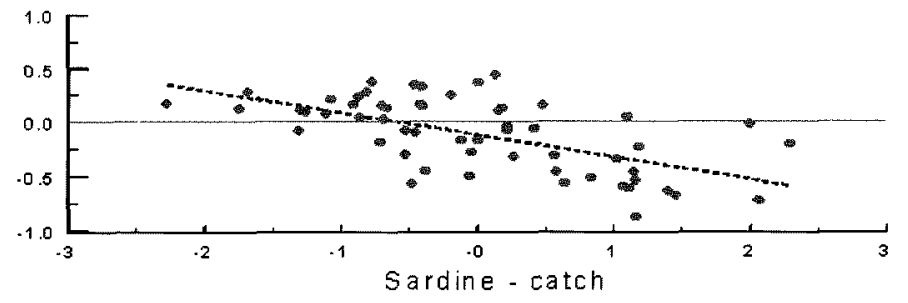

(c)

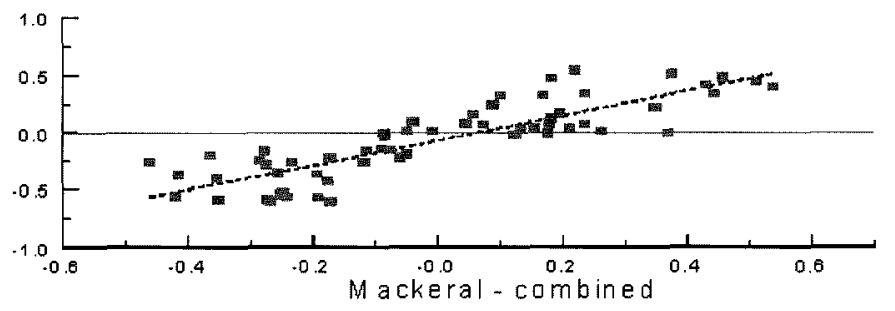

Figure 2. (a) Total Alaskan salmon catch vs. MONACLE, $r-0.73$, $n=68$; (b) Portugal sardine catch vs. MONACLE, $r=0.59, n=51$; (c) Eastern U.S. mackerel catch (from 1856) vs. MONACLE (normalized joining of 2 datasets), $r=0.85, n=0.59$. Note the vertical axes, zero line for MONACLE. the same non-stationary world. This conceptual approach attempts to move our relative perspective so that the physical and the biological series are within the same framework.

However an over-absorption in statistical analysis can be misleading. The prime objective is to understand the underlying mechanisms. For example, any relationship between northern cod catch and climate is a complex one involving population dynamics with links to basin-scale changes, such as through the North Atlantic Oscillation, to variations in the transport of Labrador Sea Water (LSW) and resulting large scale changes in water temperature. This complex mechanism is rarely expressed in terms of a single correlation. If it were, then both LSW and MONACLE (used on air temperature, Figure 3) would produce correlations with northern cod catch at a $99.9 \%$ "significance" level.

However this game is not about who has the biggest correlation. The key to this conceptual approach is that such large-scale changes in ocean properties, such as shifts in transport, should be fed back (get "reported" back to the $\mathrm{CEO} /$ atmosphere). All the published catch data are standardized (no units). Also no attempt is make to cover issues such as stock assessment or recruitment.

\section{Tuning $\ln$}

MONACLE is applied to regional, seasonal airtemperature data to produce autocorrelation time series. Figure 2 shows a comparison between Pacific total Alaskan salmon, North Atlantic mackerel and herring fish catch and each regional output of MONACLE. The use of any statistical methodology relies on verifying that such relationships have occurred other than by pure chance.

For 100 years of data a $99.9 \%$ significant correlation would be $0.32(<10 \%$ explained variance without any correction). At a $99 \%$ significant level the 100-year value is only 0.25 and for 50 years 0.35 . So by these standards these diverse species exhibit statistically significant "climate" relationships. Could we have found the correct Company minutes? More rigorous statistical analysis would require us to ask, "How significant are these correlations?" But to answer that the issue of whether a correlation has been corrected for autocorrelation becomes circular. For a varying autocorrelation is now our signal, with it we have taken a step into the non-linear, non-stationary world. We are simply comparing this measure to marine organisms that, by analogy, are the populations who have already "worked" in communications on climate, upwelling, transport, temperature and water masses should remain valid; we are just supplementing our "reference sources" for such information to include a systems own internal communications.

How this internal information becomes available is still unanswered. This study started life from an unresolved signal in autumn persistence in one of the author's prior climate studies. Subsequent comparisons focussed on autumn with fine-tuning of the season. The comparisons with the biological series are not given in the context of cause and effect. Rather it seems likely that any seasonality (e.g. autumn) in the MONACLE analysis is associated with air-sea flux mechanisms that may transfer that signal (the internal company minutes). A wider seasonal analysis is being conducted but is outside the scope of this text. That study indicates a tendency for geographical shifts in both the seasonal start month and season length (earlier and shorter season at higher latitudes) for MONACLE which would indicate an underlying climate-physical mechanism.

\section{Regional Communications}

To further reduce the element of "pure chance" we can use the previously mentioned climate-fish publications to explore a wide range of "classic" catch data. Figure 3 shows series that would give statistically significant relationships in a stationary world as well as 
indicating regional regime shifts on a 20-70 year time scale. Some of those catch series (Figures $2 b$ and 3 ) have an inverse relationship to their regional MONACLE derived index. This could occur as the feedback signal would come from the landward (cold/warm) side of a marine frontal system and the fish catch series may be located on the seaward (warm/cold) side. Further comparisons are not limited to the marine environment. A hundred years of whitefish catch in Lake Winnipeg shows the same triple peaks in both catch and MONACLE output. Other correlations, of varying strength, can be found for sturgeon in the Caspian Sea, the Japan anchovy catch, krill and Crabeater seals in the Southern Ocean, Balearic hake in the Mediterranean, and others.

With each of these comparisons the issue is not whether a "better" correlation has been achieved but whether a consistent pattern is emerging. These correlations imply no cause and effect between physics and biology. Rather they imply that the population dynamics of these species may have stayed "in tune" with largescale climate processes. If many of these major fish populations do follow climate regime shifts we can refer back to the mathematical simulation to realize how noise becomes an integral part of the system's productivity (see also Sugihara and May, 1990 and Sugihara, 1995). When either internal noise or an external agent adds "noise" at critical/stress times the anthropomorphized analogies are immediate. At these times any external factor that taxes the system beyond its resources is far more likely to force one of the local marine subsidiaries out of business. Even "extreme" events such as the 1882 tilefish kill (Marsh et al., 1999) might be seen as part of an underlying non-stationary pattern. Similarly the Swedish Bohuslan and Norwegian spring herring fisheries, the Russell cycle and the 1920s extreme influx of herring into the North Sea (all in Cushing, 1996) could form part of a 250-year pattern of regional regime changes on the European Shelf.

\section{Taking Stock}

Data analysis alone cannot confirm that the observed atmospheric persistence (feedback) is the influence of the oceans. The atmospheric scientist might still claim that "all is noise," and that any resulting random persistence is being forced into the oceans and hence experienced by its populations of workers. This study assembles the evidence for the ocean case and suggests a "thought-process" as the basis of further exploration.

This study could be considered as taking a biased approach by using published catch data that have already been identified as potentially climate related. Also catch, not catch per unit effort, has been the core of this study implying that for these examples the climatic signal was stronger than anthropogenic factors. Recruitment and population dynamics have not been touched upon. There are numerous publications that deal with these issues-by analogy from the worker's perspective. Instead this study provides an additional perspective on the complexity of non-linear systems to help bridge the gap between the physical-climate and the bio-ecosystem modelling disciplines.

\section{To Boldly Go}

In the world of human communications, language itself is non-stationary. For example the "rules" of English-grammar changed in 1998 with the re-introduction, of the split infinitive into the Oxford English Dictionary-to boldly go. So in the science world, along with the complex approaches, a few simple rulechallenging tools may allow us to better understand nature's communications.

In our thought experiment we had two executives Mother Nature and Venus communicating, but with the potential for having their own changing agendas.

- Two executives may work together, but when they have opposing agendas (signals) there is both an uncertainty and an impact on the company's actiities as reflected by the workers' productivity.

Exploring the existence of feedback between the two executives allowed us to devise a simple method to parameterize a non-linear system. Persistence or repetition in the atmosphere (Mother Nature/CEO) was the key.

- The Company minutes served as the CEO's memory of prior activities.

The Company minutes were verified as relating to the activities of the marine subsidiary. Regional indices, obtained from filtered atmospheric records, gave very good agreement with diverse, regional fish catch records.

- The agreement includes marine records previously related to processes such as upwelling, ocean transport and atmosphere circulation patterns.

- This diversity of processes links the new index to the wide range of information that can be fed back to the atmosphere/CEO.

Both the analogy and the simulations allowed us to view the occurrence of apparently random, but dramatic events in relation to how the executives were communicating.

- If the CEO and the VP are in complete unison, company directives are strong and we have a near linear system.

- When the CEO and VP are not working well together, feedback drops and the company may experience decreased profits, cutbacks and redundancies.

- Noise now becomes an integral part of the company's productivity. If noise occurs when feedback drops this could relate to abrupt changes for local marine subsidiaries, such as the collapse of a fisheries stock.

The analogy provided us with a framewrork to bring together the physical aspects of the climate system, atmosphere and ocean, with an aspect of the marine ecosystem; 


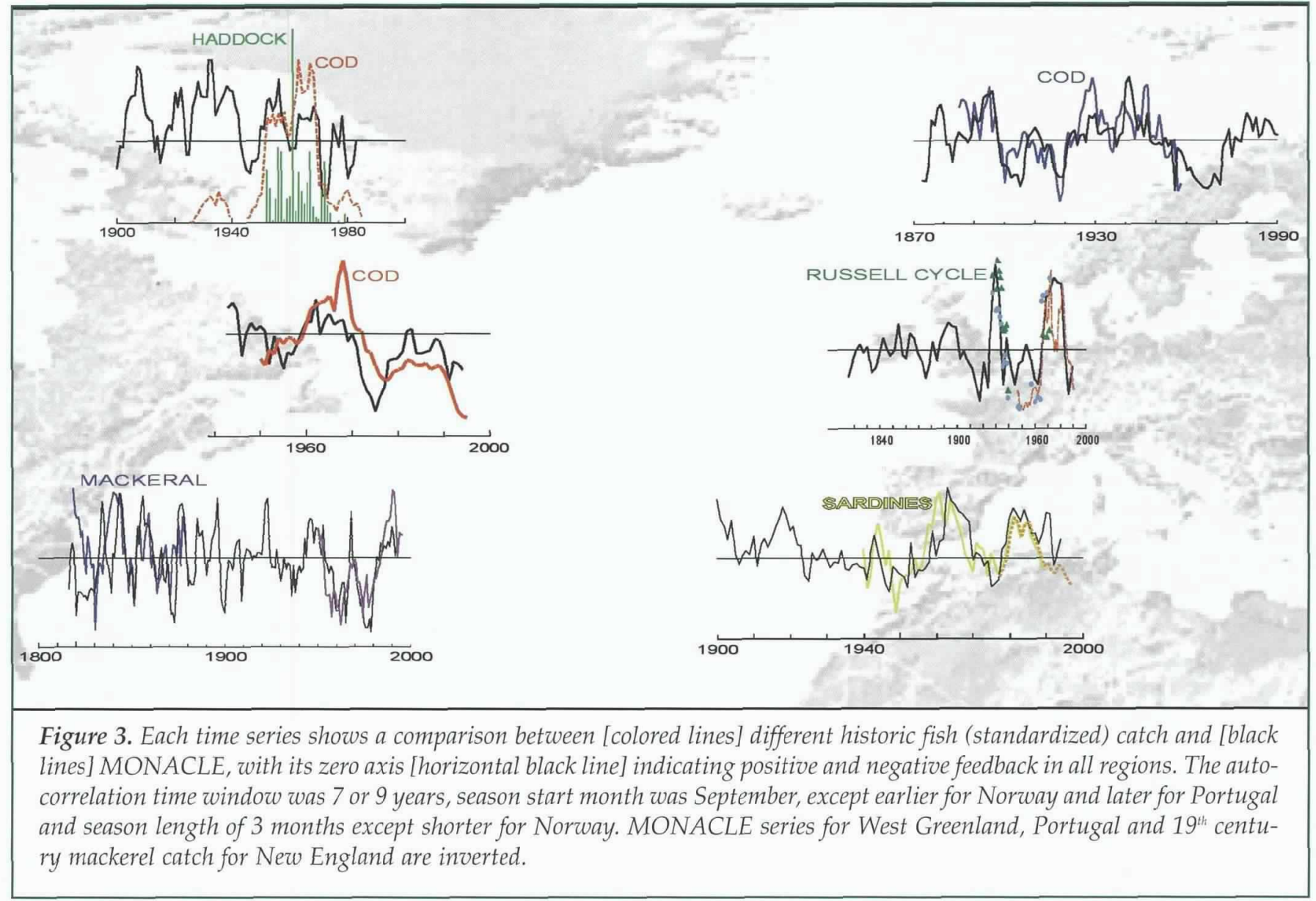

- With marine organisms that are, by analogy, the workers who must experience the non-stationary, changing dynamics of the executives' world.

- Fish stocks that may have utilized/ adapted to periods of high persistence, repeated conditions of any form and then either survived, or not, a period of apparent, sudden change in those conditions.

Anthropomorphized analogies are often viewed as inaccurate relative to inanimate analogies in that they offer too great a complexity of interactions with too many unknowns. Yet that may be more representative of our current understanding of the climate system. Just as having access to "insider" communications between company executives could profit us so could access to communications within the climate system. The acronym MONACLE relates to this underlying concept of accessing internal communications, through MOther Nature's Aquatic Chat LinE.

A "co-relation" calculation was introduced at the end of the $19^{\text {th }}$ century. Now correlation has become a standard part of any statistical toolbox. Since most statistical tools are based on assumptions of stationarity this new MONACLE technique will not be found referenced in statistical literature. The correlation calculation has remained the same for the last half century. It remains the same here; we have simply explored and then used (auto)correlation, relating information to itself in order to understand feedback. Readers who dislike the conceptual approach may view MONACLE as a moving-serial filter, but one suited to non-linear systems.

To boldly go into well researched "thought" experiments should be as routine as other approaches. Then the rest follows from where our imagination can take us. Is moisture the "network-carrier" for nature's "internal" communication system? Do numerical models already include these feedback signals? What will happen if cyclic regional feedback signals line up across oceans? What has happened in historic series when the MONACLE signal flattens out? Could different species categories (e.g. diadromous fish or crustaceans) be "tuned-in" to feedback signals transmitted at different seasons? If the feedback signal is an "environmental envelope" for some species then what does this approach imply for resource management and for any census of marine life? This autocorrelation approach used only the first-lag, what of the $2^{\text {nd }}$ or $3^{\text {rd }}$ lag? If moisture proves to be the carrier could the forests be "tunedin" to higher lag oceanic feedback?

\section{Stay Tuned-In}

The application of a new filtering technique indicates that internal information passing through the 
atmosphere-ocean climate system may be an accessible and identifiable signal rather than "noise". The opening question remains unanswered, for who initiated such signals, the atmosphere or the oceans, may be secondary to our need to incorporate feedback fully into our thinking and interpretation of climate-systems. So as we all actively catch data, chase models and pursue cause and effect perhaps we need to sit down more often in that armchair and take time to "tune-in" to MOther Nature's Aquatic Chat LinE.

\section{Acknowledgements:}

Databases have been accessed from NOAAGHCNV, DFO, NAFO, FAO, NMFS, and various publications and fisheries reports. Thanks for useful climate discussions, suggestions and data to Drs. Charles Hannah, Allyn Clarke and Ken Drinkwater. Dr. Bruce Smith, Wade Blanchard of Dalhousie University and Prof. Larry Hamilton of University of New Hampshire provided valuable supportive communications concerning this new statistical technique. Thanks for comments and suggestions on the manuscript to Drs. Peter Jones, Fred Dobson, Ken Mann, Gareth Harding, Louisa Watts at BIO and to Dr. Chris Reid of SAHFOS.

\section{References:}

Bakun, A., 1996: Patterns in the Ocean: Ocean Processes and Marine Population Dynamics. California Sea Grant College System, pp 323.

Beamish, R.J. (ed), 1995: Climate Change and Northern Fish Populations. Can. Spec. Publ. Fish. Aquat. Volume 121, pp 739.

Cushing, D.H., 1996: Excellence in Ecology. 7. Towards a Science of Recruitment in Fish Populations. Ecology Institute, Germany, 175pp.

Cushing, D.H., 1982: Climate and Fisheries. Academic Press, London and New York.

Devold, F., 1963: The life history of the AtlantoScandian herring. Rapp. P.-v. Cons. Int. Explor. Mer., 154, 98-108.

Dickson, R.R., P.M. Kelly, J.M. Colebrook, W.S. Wooster and D.H. Cushing, 1988: North winds and production in the eastern North Atlantic. J. Plankt. Res., 10, 151-169.

Dickson, R.R. and K.M. Brander, 1993: Effects of the changing wind field on cod stocks in the North Atlantic Fish. Oceanogr., 2, 124-153.

Drinkwater, K.F., G.C. Harding, W.P. Vass and D. Gauthier, 1991: The relationship of Quebec lobster landings to freshwater runoff and wind storms. In: The Gulf of St. Lawrence: Small Ocean or Big Estuary? Can. Spec. Pub. Fish. Aquat. Sci. No. 113, pp. 179-187.

Drinkwater, K.F., G.C. Harding, K.H. Mann and N. Tanner, 1996: Temperature as a possible factor in the increased abundance of American lobster, Homarus americanus, during the 1980s and early 1990s. Fisheries Oceanography, 5(3.4) 176-193.

Drinkwater, K, 2000: Changes in Ocean Climate and its
General Effect on Fisheries: Examples for the North West Atlantic. 116-136. In: The Ocean Life of Atlantic Salmon, D. Mills, ed., Fishing News Book, Blackwell.

FAO, 1997: Global Synchrony in Fish Population. In Review of the State of the World Fishery Resources: Marine Fisheries. FAO Fisheries Circular No. 920, 134-135.

Hare, S.R and R.C. Francis, 1995: Climate change and salmon production in the Northeast Pacific Ocean. In Climate Change and Northern Fish Populations. R.J. Beamish, ed., Can. Spec. Publ. Fish. Aquat. Volume 121, 357-372.

Kawasaki, T., 1992: Mechanisms governing fluctuations in pelagic fish populations. In: Benguela trophic functioning. A.I.L. Payne, K.H. Brink, K.H. Mann and R. Hilborn, eds., S. Afr. J. Mar. Sci., 12, 873-879.

Kondo, K., 1988: General trends of neritic-pelagic fish populations-a stud Japanese sardine and oceanographic conditions. Proceedings of the $25^{\text {th }}$ Anniversary Symposium Fisheries and Fisheries, Oceanography in the Coming Century, held in Tokyo Nov 10-13, 1986, 178-184.

Marsh, R., B. Petrie, C.R. Weidman, R.R. Dickson, J.W. Loder, C.G. Hannah, K. Frank and K. Drinkwater, 1999: The 1882 tilefish kill - a cold event in shelf waters off the north-eastern United States? Fisheries Oceanography, 8(1), 39-49.

McConnaughey, R.A and D.A. Armstrong, 1995: Potential effects of global climate change on Dungeness crab (Cancer magister) populations in the northeastern Pacific Ocean. In Climate Change and Northern Fish Populations. Beamish, R.J., ed., Can. Spec. Publ. Fish. Aquat. Volume 121, 291-306.

Ottestad, P., 1969: Forecasting the annual yield in sea fisheries. Nature, 185, 183.

Russell, F.S., A.J. Southward, G.T. Boalch and E.I. Butler, 1971: Changes in biological conditions in the English Channel off Plymouth during last half century. Nature, 234, 468-70.

Sugihara, G., 1995: From out of the blue. Ecology, 379, 559.

Sugihara, G and R.M. May, 1990: Nonlinear forecasting as a way of distinguishing chaos from measurement error in time series. Nature, 344, 734-741. 